\title{
Influence of holding time and pressure on tensile shear strength of resistance welded CFRTP
}

\author{
K. Tanaka, K. Okada \& T. Katayama \\ Department of Biomedical Engineering, Doshisha University, Japan
}

\begin{abstract}
In the automobile industry, CFRTP (carbon fiber reinforced thermoplastics) are expected to be used because of their superior properties such as high toughness, high productivity and high recycling efficiency. Although the composite materials allow the integral molding of complicated structures, a large number of joints such as bolts and rivets still exist for assembly of the vehicle. These fastening methods cause the increase of weight and require holes, which cause stress concentration. Since the thermoplastic resin is used for the matrix of CFRTP, molten resin by heating is possible to be used as an adhesive. The direct resistance heating welding method has been developed using carbon fibers as resistance heating elements, which are the reinforcing materials of CFRTP. In this study, the heating characteristic of the heating element was assessed by thermal imaging measurement. In order to evaluate the influence of the holding time and the holding pressure on resistance welded strength, which are the important parameters of resistance welding, tensile shear test of lap-shear specimens were conducted. The shear strength, under the conditions of $30 \mathrm{~s}$ in holding time and 1.0 $\mathrm{MPa}$ in pressure, was $21.6 \mathrm{MPa}$, is the same level as strength of the commercially available adhesive used for structures.

Keywords: CFRTP, thermoplastics, resistance welding, heating element, holding time, pressure, shear strength.
\end{abstract}

\section{Introduction}

In the automobile industry, CFRTP (Carbon Fiber Reinforced Thermoplastics) are expected to be used because of their superior properties such as high toughness, high productivity and high recycling efficiency $[1,2]$. Although the composite 
materials allow the integral molding of complicated structure, a large number of joints such as bolts and rivets are still exist for assembly of the vehicle [3]. These fastening methods cause the increase of weight and require the holes, which cause the stress concentration. Since the thermoplastic resin is used for the matrix of CFRTP, molten resin by heating is possible to use for adhesive [4]. A method using a metal mesh as a resistance heating element in the bonding interface has been developed [5, 6] and employed in aerospace industry. However, weight increase due to the use of the metal material, and the residual stress at the interface resulting from the mismatch of the thermal expansion coefficients of the different materials have been issues to be overcome. The direct resistance heating welding method has been developed by using carbon fibers as the resistance heating element, which are the reinforcing materials of CFRTP [7, 8]. Holding time and holding pressure during the resistance welding process have been a major issue [9]. In this study, the heating characteristic of the heating element was assessed by the thermal imaging. In order to evaluate the influence of holding time and the holding pressure on resistance welded strength, which are the important parameters of resistance welding, tensile shear test of lap-shear specimens were conducted.

\section{Materials and experimental procedures}

\subsection{Heating profile evaluation of the carbon fiber tow}

Unidirectional spread carbon fiber tow (Nippon Tokushu Fablic Inc., $85 \mathrm{~mm}$ long and $12.5 \mathrm{~mm}$ wide) was used as a resistance heating element. In order to clarify the heating profile of the spread carbon fiber tow by the direct resistance heating, the thermal imaging was recorded using the thermography (NEC Avio, TVS-500). Figure 1 shows the heating setup of carbon fiber tow. The temperature distribution of the heated carbon fiber tow was measured in the following conditions; the carbon fiber tow itself (Input power: $0.050 \mathrm{~kW}$ ), and the carbon fiber tow sandwiched with CFRTP laminated materials (Input power: $0.100 \mathrm{~kW}$ ). The electric power supply delivered a current to the carbon fiber tow directly using a power-supply unit (T162-6014AAH, Thamway) and an impedance converter (T010-6012A, Thamway).

\subsection{Method of resistance welding}

The CFRTP laminated materials were used for the specimens to be welded, which were $90 \mathrm{~mm}$ long, $25 \mathrm{~mm}$ wide and $2 \mathrm{~mm}$ thick. CFRTP laminated materials were molded by the high speed compression molding method [10]. As the molding condition: molding temperature was set at $270^{\circ} \mathrm{C}$ and molding pressure was set at $2 \mathrm{MPa}$. As the reinforced materials, non-crimp stitched carbon fabrics (NCF, $\left.300 \mathrm{~g} / \mathrm{m}^{2},\left[0^{\circ} / 90^{\circ}\right]\right)$, which are PAN-based carbon fibers being stitched together by polyester sewing thread, were used. Non-woven fabric (prototype, Kuraray Co., Ltd., Japan $50 \mathrm{~g} / \mathrm{m}^{2}$ ) of Polyamide 6 (PA 6, Ube Industries, Ltd., Japan) were used for matrix of the specimens. 


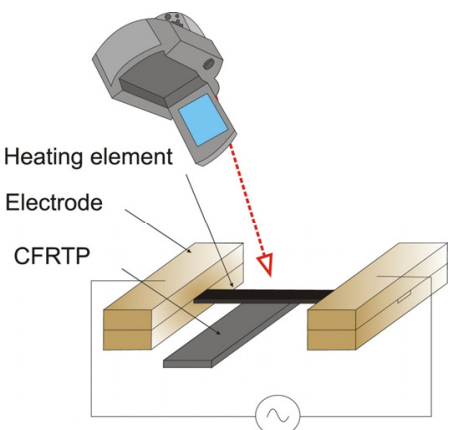

(a)

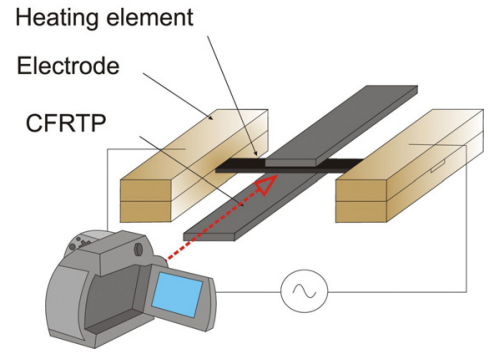

(b)

Figure 1: Heating setup of the carbon fiber tow: (a) carbon fiber itself, (b) carbon fiber tow sandwiches with the CFRTP laminated materials.

Figure 2 shows the preparation of the specimens to be welded. The heating element, unidirectional spread carbon fiber tow, and non-woven fabrics of resin were laminated so that volume fraction of fiber was 50\%. Figure 3 shows the schematic of the resistance welding. When the temperature at the welding area rises to $220^{\circ} \mathrm{C}$ which is the melting point of PA 6 , thermoplastic matrix starts to melt. The input power supply was regulated so as to be the target temperature of $260 \pm 20^{\circ} \mathrm{C}$, while the temperature of the welding area was measured by the thermography. The holding time was defined as which the time after the temperature was reach to $260^{\circ} \mathrm{C}$. After melting of the matrix by the certain holding time, the welding pressure was applied. The condition of the welding pressure $(0.1,1.0,2.0[\mathrm{MPa}])$ and the holding times at the maximum temperature $(30,60,120[\mathrm{~s}])$ used in this study are shown in Table 1.

Tensile tests were conducted by using a universal testing machine (Autograph AG-100kN, Shimadzu Corporation) based on JIS-K6850 [11].

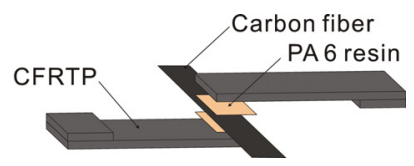

Figure 2: Lamination of the specimens.

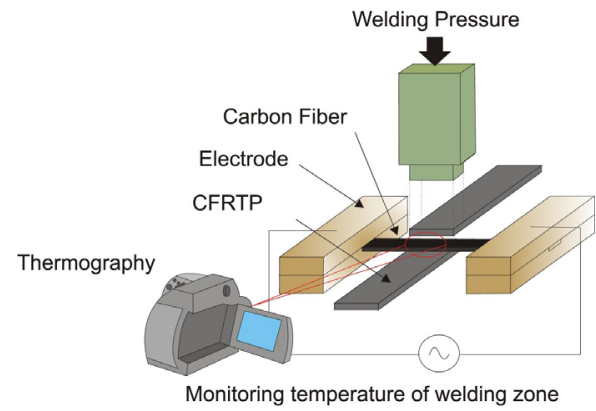

Figure 3: Schematic of experimental setup of resistance welding. 
Table 1: Welding conditions.

\begin{tabular}{|c|c|c|}
\hline & Holding time [ s ] & Pressure [MPa ] \\
\hline CF1 & 30 & \multirow{2}{*}{1.0} \\
\cline { 1 - 2 } CF2 & 60 & \\
\hline CF3 & 120 & 0.1 \\
\hline CF4 & 30 & 2.0 \\
\hline CF5 & & 2.0 \\
\hline
\end{tabular}

\section{Results and discussion}

\subsection{Heating profile evaluation of the carbon fiber tow}

Figure 4 shows the temperature distribution of the surface of the carbon fiber tow. Domain A shown in Figure 4 is the welding area and the temperature distribution of that area is shown by the histogram in Figure 5. The frequencies that are above the $220^{\circ} \mathrm{C}$ which is melting point of PA6 matrix occupy around $70 \%$ of the domain A. Figure 6 shows the slant thermographic view of the carbon fiber tow sandwiched with the CFRTP laminated materials as shown in Figure 3. Figure 7 shows temperature distribution of the outside (Line A and B) and the central part (Line $\mathrm{C}$ ) of the portions corresponding to the carbon fiber tow as showed by the thermographic in Figure 6. The temperature distribution of in welding zone is within the range of the target temperature range of $260 \pm 20^{\circ} \mathrm{C}$ shown in Figure 7.

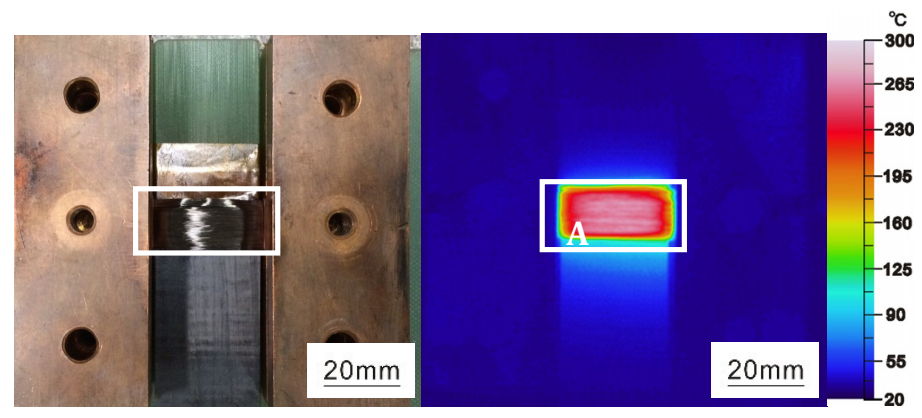

Figure 4: Temperature distribution of carbon fiber tow. 
High Performance and Optimum Design of Structures and Materials II 355

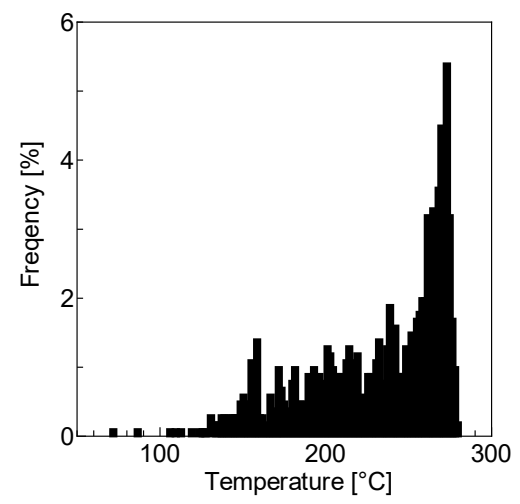

Figure 5: Frequency of temperature of carbon fiber tow.

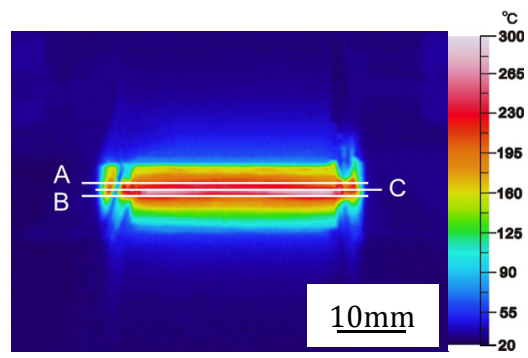

Figure 6: Thermograph image of welding zone.

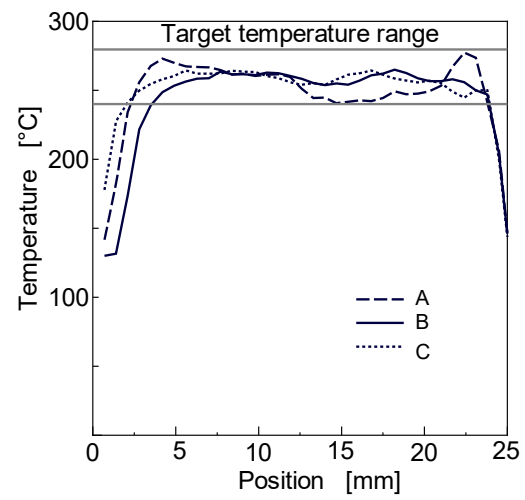

Figure 7: Temperature distribution of welding zone.

\subsection{Tensile shear strength of resistance welded specimen}

Figures 8 and 9 show the tensile shear strength of the resistance welded specimens that were welded in different holding times and welding pressures. The highest 
tensile shear strength of $21.6 \mathrm{MPa}$, was obtained in the welding pressure of 1.0 MPa and holding time of $30 \mathrm{~s} \mathrm{(CF} \mathrm{1).} \mathrm{The} \mathrm{commercially} \mathrm{available} \mathrm{adhesive}$ used for structures is around 20.7-24.1 MPa. The obtained tensile shear strength is comparable to this strength. Figure 10 shows the schematic drawing of the observed surface of the welded specimens after tensile shear tests. Figure 11 shows the surface of the specimens observed as shown in figure 10 (a) for different holding time. In the case of the long holding time, $60 \mathrm{~s}$ and $120 \mathrm{~s}$, the surface of specimens was melted and damaged by the heat transfer from the heating element. Since the specimens were damaged and deformed by a long holding time, the low shear tensile strength was obtained in the case of a long holding time of $120 \mathrm{~s}$. Figure 12 shows the surface of the specimens observed as shown in figure 10(a) for different pressure. No damage on the surface was observed in all conditions. Figure 13 shows the fracture surfaces of the welded specimens at different pressure. Under the condition of CF 1, which has the highest tensile shear strength, interfacial failure mainly occurred at the interface between specimens and welded zone, and crack also passed in the welded CFRTP as described in figure 14(a). This fracture surface is correspond to the highest tensile shear strength of CF 1. On the other hand, under the condition of CF 4 and CF 5, intralaminar fracture occurred as described in figure 14(b). On the fracture surface of CF 4, the carbon fibers that were used as the resistance heating element were exposed on the fracture surface. Due to the low pressure in CF 4, impregnation of resin was poor and CF 4 showed lower tensile shear strength. On the fracture surface of CF 5, the carbon fibers spread and had waviness. The high pressure during the welding is considered to cause the resin flow outward welding zone and low tensile shear strength. The optimum welding pressure exists in resistance welding.

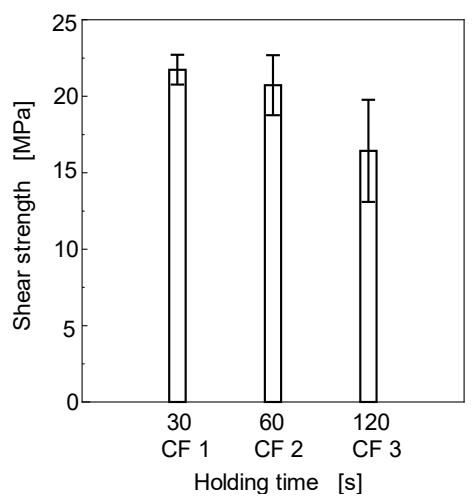

Figure 8: Influence of holding time on shear strength (pressure: 1.0 MPa).

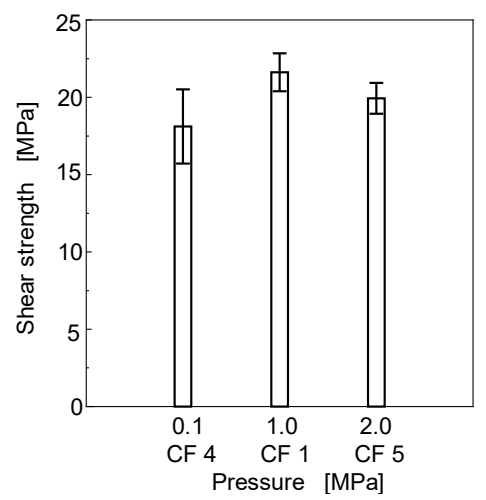

Figure 9: Influence of pressure on shear strength (holding time: $30 \mathrm{~s})$. 


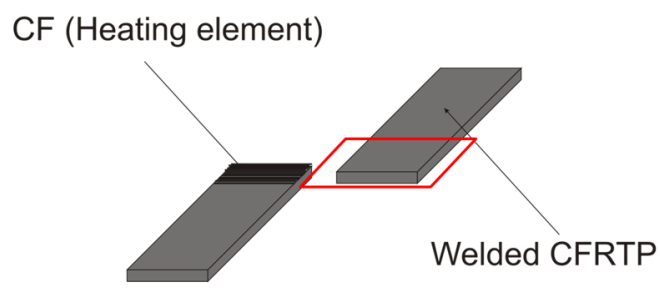

(a)

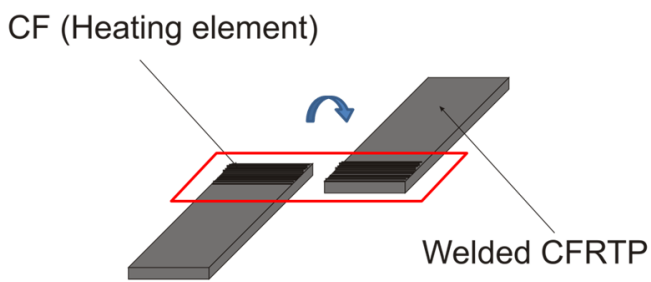

(b)

Figure 10: Observation of Welded CFRTP: (a) surface observation of the welded specimens, (b) fracture surface observation of the welded specimens.

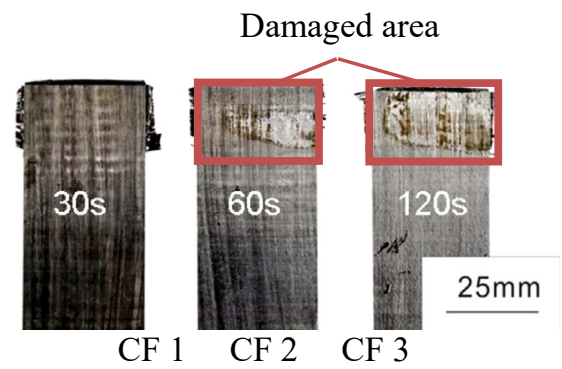

Figure 11: Welded specimens at different holding time.
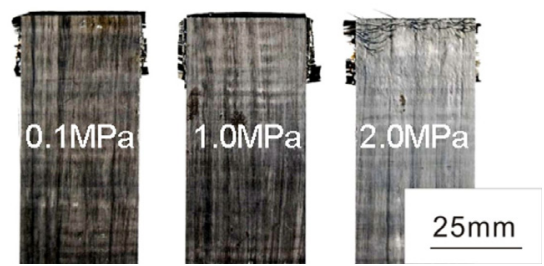

CF 4 CF 1 CF 5

Figure 12: Welded specimens at different pressures. 


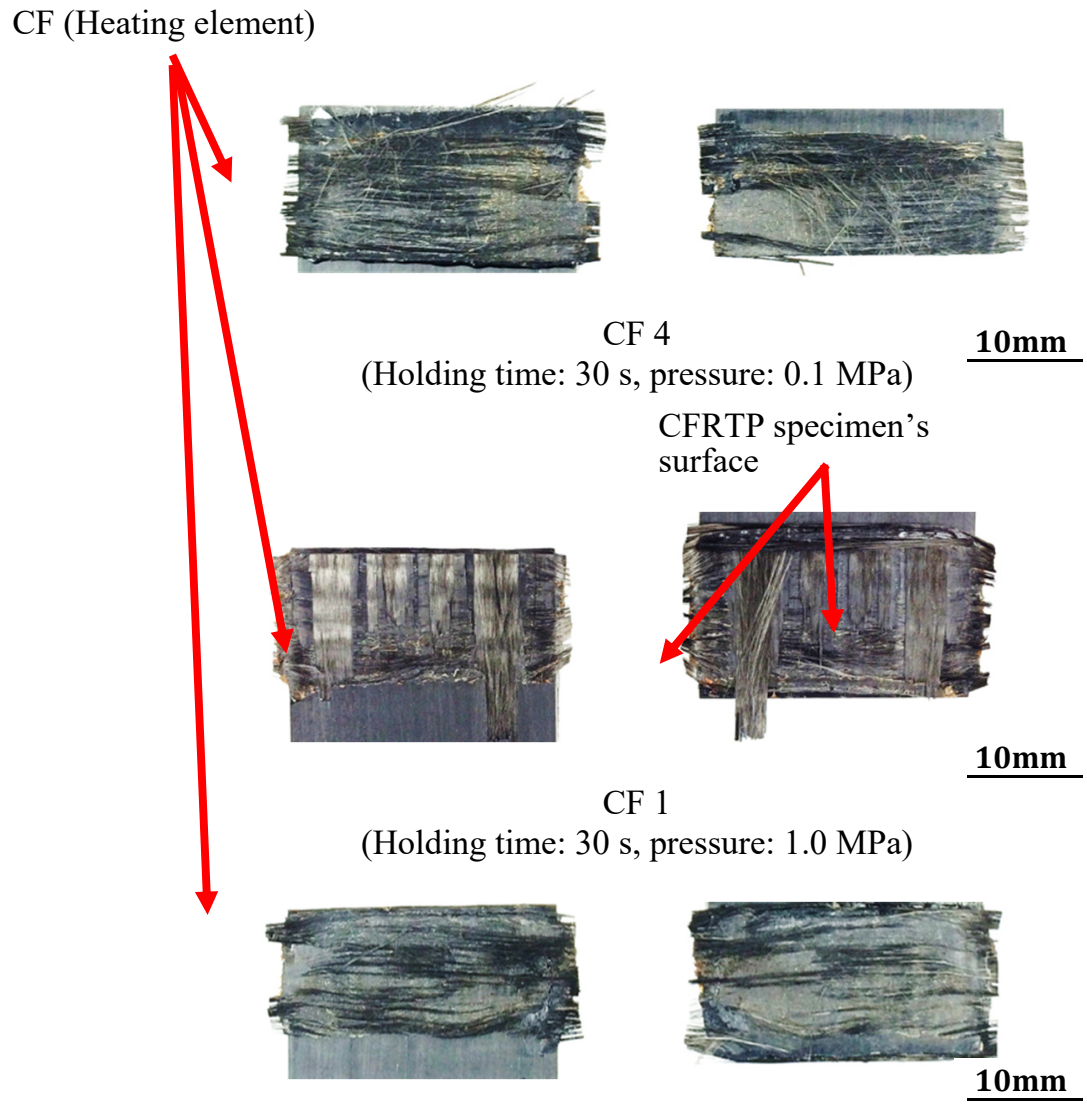

CF 5

(Holding time: $30 \mathrm{~s}$, pressure: $2.0 \mathrm{MPa}$ )

Figure 13: Observation of the fracture surface.

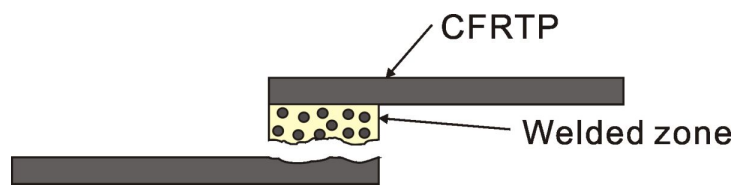

(a)

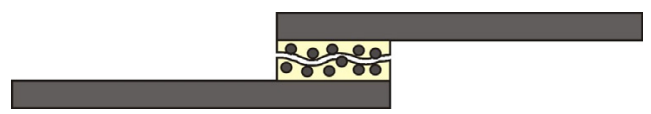

(b)

Figure 14: Failure mode of the tested CFRTP specimens: (a) interfacial fracture, (b) intralaminar fracture. 


\section{Conclusion}

The heating characteristic of the heating element, carbon fiber tow, for the direct resistance heating welding method was assessed by the thermal imaging. In order to evaluate the influence of holding time and the holding pressure on resistance welded strength, which are the important parameters of resistance welding, tensile shear test of lap-shear specimens were conducted. The tensile shear strength, under the conditions of $30 \mathrm{~s}$ in holding time and $1.0 \mathrm{MPa}$ in pressure, was $21.6 \mathrm{MPa}$, is the same level as strength of the commercially available adhesive used for structures.

\section{References}

[1] Ishikawa, T., Overview of Carbon Fiber Reinforced Composites (CFRP) Applications to Automotive Structural Part, - Focused on Thermoplastic CFRP- Japan Society for Precision Engineering, Vol. 81, No. 6, pp. 489493, 2015.

[2] Composites penetration growth in Automotive: towards mass production 2010-2020 trends and forecasts, JEC Composites, pp. 13-22, 2011.

[3] Amancio-Filho, S. T. \& Santos, J. F. D., Joining of Polymers and PolymerMetal Hybrid, Polymer Engineering and Science, Vol. 49, pp. 1461-1476, 2009.

[4] Yousefpour, A., Fusion Bonding/Welding of Thermoplastic Composites, Journal of Thermoplastic Composite Materials, Vol. 17, pp. 305-335, 2004.

[5] Hou, M., Yang, M., Beehag, A., Mai, Y. \& Ye, L., Resistance welding of carbon fibre reinforced thermoplastic composite using alternative heating element, Composite Structures, Vol. 47, pp. 667-672, 1999.

[6] Dube, M., Hubert, P., Yousefpour, A. \& Denault, J., Fatigue failure characterization of resistance welded thermoplastic composites skin/stringer joints, Fatigue, Vol. 31, pp. 719-725, 2009.

[7] Ageorges, C. Ye, L. \& Hou, M., Experimental investigation of the resistance welding for thermoplastic-matrix composites. Part I: heating element and heat transfer, Composites Science and Technology, Vol. 60, pp. 1027-1039, 2000 .

[8] Shi, H., Villegas, I. F., Octeau, M., Bersee, H. E. N. \& Yousefpour, A., Continuous resistance welding of thermoplastic composites: Modelling of heat generation and heat transfer, Composites Part A, Vol. 70, pp. 16-26, 2015.

[9] Stavrov, D. \& Bersee, H. E. N., Resistance welding of thermoplastic composites - an overview, Composites Part A, Vol. 36, pp. 39-54, 2005.

[10] Tanaka, K., Kohashi, N., Kinoshita, Y., Katayama, T. \& Uno, K., Compression Molding of Carbon Fiber Reinforced Thermoplastics Using Non-Woven Stitched Multi-Axial Cloth by Means of Induction Heating System, The Society of Materials Science Japan, Vol. 58, No. 7, pp. 642648, 2009.

[11] JIS-K6850, www.testpanel.co.jp/product/testpanel/bond/jisk6850.html 